\title{
The Intellectualisation of African Languages for Higher Education
}

\section{Kwesi Kwaa Prah}

\begin{abstract}
This article was originally presented as a keynote Address at the University of KwaZulu-Natal's Language Planning and Development Office (ULPDO) language symposium from 19-20 October 2015 at the Unite Building, Howard College, Durban, on the theme: Advancing the Intellectualization of African Languages in Higher Education. The position paper examines the challenge of how to intellectualise African languages and bring them up to speed with the linguistic techniques of modernity and advanced contemporary thought.
\end{abstract}

Keywords: Intellectualisation; African languages; Higher Education

\section{Introduction}

In recent times, the centrality of African languages in transforming society has been acknowledged across the continent and beyond in various contexts and on different platforms. It is also recognised that, without the intellectualisation of our languages, there is little hope of Africans achieving sustainable development. In my view, these are most welcome developments. Ultimately, our languages as intellectualised media are culturally the single most important instrument for the empowerment of society and the optimisation of human capital in Africa.

For those who have long been converted to the belief that African languages are crucial to African social and economic development, there is little need to argue that we need to swiftly and effectively enable our languages to develop scientific and technological capacity, rational, logical approaches, and analytical techniques. The real challenge is how to intellectualise African 
languages and bring them up to speed with the linguistic techniques of modernity and advanced contemporary thought. As with many other human considerations, in principle the solutions are universal, but should be grown in African cultural conditions. We do not have to reinvent the wheel and should not regard ourselves as unique. However, while we should learn from the experience of others, such lessons should be adapted to African historical circumstances, cultural characteristics and contextual situations.

The experience of Europe and Asia in particular speaks volumes on this matter. Post-colonial Asia may offer us a great deal that we can learn from, not by crude imitation or indiscriminate adoption, but by adaptation that recognises the primacy of our cultural heritage; builds on what we already have; recognises our historical genius and creates variations on comparative universal themes. The primary stumbling block is the inhibiting effect of cultural neo-colonialism in contemporary Africa which causes many to believe that if something is not done in the Western way, specifically the way the colonialists did it, it is doomed to failure.

Asian societies have also battled with these stumbling blocks and have made more consistent progress in the past 70 years than African countries. In the first place, post-colonial Asia has moved away from the colonial language. This process has been a democratic one that embraces broad social goals and involves planned and carefully timed cultural empowerment where people's languages take centre stage in their lives.

This has not meant that Asian societies have completely rejected Western languages. Rather, they have replaced the role of colonial languages in education and development with native languages and cultures. The shift from Western linguistic and colonial tutelage to autonomous indigenous languages of education and social intercourse has enabled the development and transformation of Asian societies that we see today. In countries like Vietnam, Malaysia, Indonesia and Korea, indigenisation of the language of development in education has opened the doors to development and emancipation.

\section{Intellectualised Language}

A simple but apt definition of an intellectualised language is a 'language which can be used for educating a person in any field of knowledge from kindergarten to the university and beyond' (Sibayan 1999:229). Nolasco (2009) argued that, 
in the Philippines, where society has been grappling with the intellectualisation of Tagalog for decades, '...we will never be able to develop our languages for higher thinking unless we begin basic literacy and education in them. It isn't a matter of first intellectualizing a language before using it. We can only intellectualize a language by using it' (cited in Multilingual Philippines 2009:1). The first condition for the intellectualisation of a language is that it must have a literate social base; it must be written. Literacy is thus a primary condition for intellectualisation.

As a technique, language expresses itself in two historical forms; it is orally constructed and also manifests as literate rendering. Historically, the first has preceded the second. However, these two forms of language-use overlap and co-exist. Apart from historically preliterate societies, there are hardly any societies in which orality and literacy do not co-exist and interact. However, as societies advance technologically, scientifically and otherwise, literacy and its related practices supersede orality. Literacy has enabled and enhanced the deposition and accumulation of knowledge and information. It has also minimised personal communication and printing has created a space between communicators. It can be argued that without literacy, human societies' capacity to technologically and scientifically transform is limited. The work of the 'great divide' theorists over the past 50 to 60 years offers useful insights on the dialectics of orality and literacy (Ong 1982; Havelock 1963; McLuhan 1962; Lévi-Strauss 1966; Goody 1963; Goody 1987). In sum, it is argued that, in broad terms, the difference between literate and oral societies represents the gap between 'civilization' and 'barbarism' (Prah 2015).

The notion of the 'great divide' has been the subject of intense debate over the years. The main criticism is that it lends itself to simplistic and crude binarism and that the relationship between literacy and orality is more interactive and inter-connected or more historically continuous. These critical views are thus frequently described as 'continuity theories' (Prah 2015; Street 1986; Finnegan \& Horton 1973; Finnegan 1988; Chandler 1995; Scribner \& Cole 1981).

Beyond the primary requirement of literacy, intellectualisation depends on a number of other enabling conditions. The first is availability and access to all knowledge, past, present and future. In other words, we should know what we have; what exists as knowledge, and where it is to be found. All such information must be captured in retrievable form, i.e., in print, audio visual, the World Wide Web, digital storage, etc. These are all literate forms 
of storage. Secondly, society and all its constituencies should appropriate and use the intellectualised language; these include government organisations; the education system at all levels; business, commerce, and industry; professions such as engineering, medicine, law, agricultural sciences, etc.; mass communication and creative writing; foreign relations and international business banking, trade and commerce; and information technology (Sibayan 1999).

The development of discipline-specific terminology is crucial to the intellectualisation of a language. The paucity of such specialised terminology is often cited as the reason why African languages cannot be used as languages of teaching and learning. In South Africa the University of KwaZulu-Natal (UKZN), through the University Language Board (ULB), has devoted considerable resources to the development of terminology in Administration, Architecture, Psychology, and Nursing (to name but a few disciplines). It should be noted, however, that the process of developing terminology is a complex and arduous one, which has to be carefully and competently managed (Khumalo 2016).

The sectors cited above are specialised ones, with knowledge and information couched in specific technical language, i.e. registers. It is important to note that such specialised sectors are institutionally supported by structures such as academies, schools, universities etc.; governmental structures; business, banking and commerce, and a societal base which has a collective interest in the production and reproduction of such knowledge.

The development of registers is one of the most taxing features of the intellectualisation of languages. A central or centralised institutional base must exist or be created to serve this purpose. In its absence, different people and institutions might easily and inadvertently work at cross-purposes. A crucial part of the work that needs to be undertaken under the auspices of such a body or bodies is the creation and formulation of terminology for new areas of knowledge and reality. This work must not be done with an overly elitist ethos. When society uses its own creativity to collectively coin a term that becomes part of everyday language, it is disingenuous to attempt to impose unknown and unpopular coinage.

Grammar books, dictionaries and glossaries are vital to the success of language intellectualisation. Particular emphasis needs to be placed on the production of monolingual dictionaries. Throughout modern Africa, monolingual dictionaries are valued less than bilingual dictionaries featuring an 
African and a colonial language. The implication is that our prime concern is to communicate with the rest of the world and not with ourselves. Higher educational institutions are best suited to the tasks involved in many of the above areas of work.

As the present rolls into history, societies change from present to past tense. Language comes to terms with social metamorphosis, finding new words to comprehend these realities. Social development is marked in the dynamics of language, and ultimately in words. The evolution of language maps social transformation. When science and technological changes occur, the vocabularies of science are absorbed into society's vocabulary. The development of meta-language, i.e., a language or symbolic representation or information about a language which is used to discuss, explain or analyse another language or symbolic system, mirrors the growth of science and technology in society. In other words, the thematic emphasis that may exist or emerges in meta-language in the given society refers directly to new conditions and realities in the scientific and technological culture of that society. Over time, meta-language is slowly colloquialised and mainstreamed.

Local languages are also the repositories of indigenous knowledge. When extraneous knowledge is absorbed and incorporated into local languages, it becomes part of the fund of indigenous knowledge; i.e., it is indigenised. Indigenous knowledge thus can be and is intellectualised. When we use our languages for education and import intellectualised capacity to them, the social gap between the colonially received knowledge constituency and indigenous knowledge constituency is bridged. The use of our languages for education and general social practice therefore implies the intellectualisation of indigenous knowledge.

\section{Harmonisation and Standardisation of Orthographic Conventions}

In recent decades, it has also been acknowledged that if we want to produce literature and related materials in large, economically viable quantities, we first need to harmonise existing orthographies. When the Centre for Advanced Studies of African Society (Cape Town) was created in 1997, the immediate issue it addressed was the bases for the contention that a huge number of languages are spoken on the African continent; the 1980 Lome Seminar on the 
Problems of Language Planning in a Bi- or Multilingual Context estimated that the figure amounted to between 1,250 and 2,100. This explained the argument that Africa is a 'Tower of Babel' (Prah \& Miti forthcoming).

However, the veracity of this conclusion has been called into question. Indeed, when Africa's size is taken into consideration, as the second largest continent after Asia, the variation in speech forms across most of the continent hardly exceeds those found elsewhere. The largest degree of variation is found in what is called 'the fragmentation belt' which roughly runs from the Senegambia to Ethiopia and down to the latitude of North Tanzania. More importantly, the overwhelming majority of so-called languages in Africa are in fact dialectal variants of 'core languages'. Due to the fact that these mutually intelligible variations were introduced as written forms by different, often rival missionary groups keen on preserving 'their flock' from evangelical poaching, on paper there appear to be differences in speech forms that can easily be written in the same way, enabling their accessibility to larger literate communities.

A network of academics, language activists and language practitioners numbering about 150 throughout Africa has succeeded in harmonising and standardising the orthographies of over $80 \%$ of the population of sub-Saharan Africa. To date, monolingual dictionaries have been produced for nine languages: Akan, Ateso/Nkarimojong, Ciyawo, Dhopadola, Silozi, Kikaonde, Acholi, Luvale and SiSwati and 39 language clusters have been harmonised. Numerous monographs using the new orthographies have been produced for a wide variety of languages. These cover issues like sanitation, water, women's rights, democracy, health, disease, etc. and can be used for adult literacy classes and to empower marginalised populations with knowledge that is crucial in their lives. The harmonisation and standardisation of orthographies is the first step towards a rational approach to the intellectualisation of African languages. It addresses the chaotic and fluid counts of African languages that are frequently offered and, on hard linguistic grounds it classifies these languages on the basis of structural, lexical affinities and mutual intelligibility.

The example of Bahasa in Malaysia is salutary. A significant development on the road to the intellectualisation of Bahasa Melayu (BM) occurred in 1972 with the formation of a committee and the subsequent Malaysia-Indonesia Spelling Agreement to standardise the spelling system for the two countries. This simplified the assimilation of scientific terms from foreign sources (especially English) into BM and paved the way for the 
intellectualisation of Bahasa (Muhamad, Kamis \& Junoh 2003). Like most British colonial territories in Africa, Malaysia inherited an education system based on English. In 1965, the oldest university in the country, the University of Malaysia, adopted a bilingual system, with BM for Arts subjects and English for Science and Technology. Over time, this became a completely monolingual system, using only BM. By 1983, all subjects including the sciences could be conducted in BM in all public universities. In 1969, a national language policy was implemented, based on the premise that, if the status of the Malay language was not upgraded, Malays' political and economic status would never improve and national cohesion would not be achieved. One of the main developments was a memorandum to the government regarding the establishment of a public university that solely uses BM as the medium of instruction. This led to the birth of Universiti Kebangsaan Malaysia (the 'National University of Malaysia') in 1970. Following this development, all other universities that were established were required to use $\mathrm{BM}$ as the medium of instruction, in keeping with the National Education Policy (Gill n.d.).

\section{Steps to be Taken}

Overall language planning should precede the creation of the many institutions and steps I have identified as necessary for the intellectualisation of our languages. The plan would set out a vision and outline the broad steps to be taken as well as a strategy to utilise local languages for education and development. The vision should be geared towards the emancipation and empowerment of the populace so that people are better able to fulfil their aspirations and perform to their full potential free from existential constraints.

From the onset of colonialism to date, language planning in Africa has been unduly favourable and accommodative of the status and place of colonial languages in our lives. We need to reverse this and move in the direction of language policies that take us forward in developing improved life conditions with conceptual tools drawn from and equipped with data rooted in the African experience and realities.

Notions like bilingualism that are borrowed from Western sources with limited applicability and relevance to African societies are unfortunately frequently applied. Together with Birgit Brock-Utne we have in the past criticized these crude conceptual importations that are employed to explain and 
analyse African realities (Prah \& Brock-Utne 2009; Makalela 2015). Prah and Brock-Utne write that; 'even if an African child were to be trained in school, in two African languages, s/he would not be called bilingual. The concept of bilingual teaching in the African context seems to be reserved for a situation where one of the languages is an ex-colonial language. It is my experience that this situation contributes greatly to the "stupidification" of African children" (Prah \& Brock-Utne 2009:19).

In the same volume, I note that peddling the myth of the feasibility of additive bilingualism as language in education policy for Africa is misplaced. It is frequently made to appear as if this is a new tailor-made paradigm. In matter of fact, in as far as its objective of effective dual-language acquisition in education is concerned, it has been offered in different shapes and forms since the early years of colonialism and missionary-led education in Africa. In its more recent reinvention, it is a paradigm borrowed mainly from Western and particularly Canadian social circumstances, which is now being presented as a model for African educational conditions. Justification for bilingualism in African education is inherently unsound and defective. Africans are for the most part multilingual (Prah \& Brock-Utne 2009).

Multilingualism is a hallmark of Africa and its growth has been spectacular in the past few decades, particularly in urban areas. This reality is an enormous advantage which can be utilised in our collective African interest. Most Africans speak more than one language and many have acquired languages in primary group situations; they can thus be treated almost like 'home languages'; a term which in many instances better reflects African realities than 'mother tongue'. The multilingual character of African society should be factored into language planning in such a way that from primary to secondary and tertiary levels, people are sufficiently exposed to the range of languages in the locality, region and further afield. If languages are taught over extended periods of plus or minus six years as classroom subjects and not as the language of instruction, by the sixth to seventh year of exposure, learners will be able to demonstrate sufficient working knowledge to be able to pursue academic studies in them, once again, not as the language of instruction. This occurs in European countries such as The Netherlands, Belgium, Switzerland, Norway, Sweden and Germany.

A major component of the organisation of an intellectualised language-based society is the creation of a translation industry. Modern societies have a large body of translation intelligentsia who are able to render 
foreign ideas and literature into local languages. The depth and extent of this capacity determines the degree to which foreign-derived knowledge is or can be 'domesticated'. Closely allied to this issue is the question of the economic profitability of literature production in local languages. Where there is a premium on literature in all academic disciplinary areas in local languages, the use of local languages is societally treasured. Such literature should not be restricted to scholarly materials but include popular literature and news publications.

As the pinnacle of the education system, higher educational institutions should take the lead in enabling the intellectualisation of African languages. Departments should be established to provide instruments and materials and dedicated specialist posts should be created. With its superior infrastructure, South Africa is well-placed to lead this endeavour. If we succeed, others will follow. We have also the advantage in that Afrikaans offers a technical example of how to go about this task.

Afrikaans developed from standardisation to successful intellectualisation between 1913 and the mid-1930s. I have often described it as one of the three linguistic miracles of the past 100 years, with the others being Bahasa and Modern Hebrew. Over a period of little more than 20 years, the Afrikaans language was transformed from primary standardisation to a language capable of discussing the most advanced contemporary scientific knowledge. When the National Party came to power in 1948, more resources were devoted to this exercise. Much can be learnt from the practical process of this effort.

\section{References}

Brock-Utne, B. 2015. Language, Literacy and Democracy in Africa. In Makalela, L. (ed.): New Directions in Language and Literacy Education for Multilingual Classrooms in Africa. Cape Town: Casas Book Series No.115. Chandler, D. 1995. Great Divide Theories in Biases of the Eye and Ear. Available at: http://visual-memory.co.uk/daniel/Documents/litoral/lito ral1.html. (Accessed on 25 September 2015.)

Finnegan, R. 1973. Literacy versus Non-literacy: The Great Divide? Some Comments on the Significance of 'Literature' in Non-literate Cultures. In Finnegan, R. \& R. Horton (eds.): Modes of Thought. London: Faber \& Faber. 
Finnegan, R. 1988. Literacy and Orality: Studies in the Technology of Communication. Oxford: Basil Blackwell.

Gill, S.K. n.d. Language Policy and Planning in Higher Education in Malaysia: A Nation in Linguistic Transition (Mimeo). Available at: http://ccat.sas. upenn.edu/plc/clpp/proposal/SaranMalaysia.htm. (Accessed on 13 August 2014.)

Goody, J. \& I. Watt 1963. The Consequences of Literacy. Comparative Studies in Society and History 5,3:304-345.

Goody, J. 1987. The Interface between the Written and the Oral. Cambridge: Cambridge University Press.

Havelock, E. 1963. Preface to Plato. Cambridge, Mass: Harvard University Press.

Khumalo, L. 2016. The Advancement of African Languages in Higher Education. Presentation at $5^{\text {th }}$ Research and Innovation Week, 01 March. Pretoria: Senate Hall, UNISA. Muckleneuk Campus.

Lévi-Strauss, C. 1966. The Savage Mind. Chicago: University of Chicago Press.

McLuhan, M. 1962. The Gutenberg Galaxy: The Making of Typographic Man. Toronto: University of Toronto Press.

Muhamad, M., M. Kamis, \& A.M. Junoh, 2003. Bahasa Melayu versus English: A Love-hate Relationship? Paper presented at SCUTREA, 33rd Annual Conference, 1-3 July, University of Wales, Bangor.

Multilingual Philippine 2009. Intellectualizing a Language. Available at: https://mlephil.wordpress.com/2009/06/19/intellectualizing-a-language/. (Accessed on 19 June 2009.)

Ong, W.J. 1982. Orality and Literacy. The Technologizing of the Word. London: Methuen.

Prah, K.K. \& B. Brock-Utne (eds.) 2009. Multilingualism. An African Advantage. A Paradigm Shift in African Languages of Instruction Policies. Cape Town: CASAS Book Series No. 67.

Prah, K.K. \& B. Brock-Utne 2009. Introduction, Multilingualism: An African Advantage. In Prah, K.K. \& B. Brock-Utne (eds.): Multilingualism: A Paradigm Shift in African Language of Instruction Policies. Cape Town: CASAS Book Series No. 67.

Prah, K.K. 2009. A Tale of Two Cities. Trends in Multilingualism in Two African Cities: The Cases of Nima-Accra and Katutura-Windhoek. In Prah, K.K. \& B. Brock-Utne (eds.): Multilingualism. An African 
Advantage. A Paradigm Shift in African Languages of Instruction Policies. Cape Town: CASAS Book Series No. 67.

Prah, K.K. 2015. Language, Literacy and the African Development Challenge. Mimeo. Keynote Address to the $2^{\text {nd }}$ International Language and Literacy Symposium 8th - 10th August 2015. Witwatersrand University.

Prah, K.K. \& L. Miti (eds.) [Forthcoming]. Deconstructing the African Tower of Babel. Between the Harmonization and Fragmentation of African Language Orthographies. Cape Town: CASAS Book Series No. 120. Scribner, S. \& M. Cole 1981. The Psychology of Literacy. Cambridge, Mass: Harvard University Press.

Sibayan, B.P. 1999. The Intellectualization of Filipino and other Essays on Education and Sociolinguistics. Manila: The Linguistic Society of the Philippines. De La Salle University Press.

Street, B. 1986. Literacy in Theory and Practice. Cambridge: Cambridge University Press.

Kwesi Kwaa Prah The Centre for Advanced Studies of African Society Cape Town kkprah@casas.co.za 